\title{
PROPOSTA DE IMPLEMENTAÇÃO DO JOB ROTATION PARA PADRONIZAR O NÍVEL DE SERVIÇO DO SETOR ADMINISTRATIVO: ESTUDO DE CASO COLÉGIO DOM BOSCO- LESTE
}

\section{ARTIGO ORIGINAL}

MARTINS, Rarissa Romana Nogueira ${ }^{1}$, REIS, Alexandre Silva dos ${ }^{2}$, PINHEIRO, Silvana Viana ${ }^{3}$, ALMEIDA, Victor da Silva ${ }^{4}$, LEITE, Ygor Geann dos Santos ${ }^{5}$, ROBERTO, José Carlos Alves 6

MARTINS, Rarissa Romana Nogueira. Et al. Proposta de implementação do Job rotation para padronizar o nível de serviço do setor administrativo: estudo de caso colégio Dom Bosco- Leste. Revista Científica Multidisciplinar Núcleo do Conhecimento. Ano. 06, Ed. 11, Vol. 02, pp. 19-39. Novembro 2021. ISSN: $2448-$ 0959 Link de acesso:

https://www.nucleodoconhecimento.com.br/administracao/padronizar-o-nivel, DOI: 10.32749/nucleodoconhecimento.com.br/administracao/padronizar-o-nivel

\section{RESUMO}

O presente artigo teve como propósito realizar um estudo de caso na Inspetoria Salesiana Missionária da Amazônia, uma instituição de ensino. Desta forma, considerando que, por meio do diagnóstico organizacional foi possível identificar baixo desempenho no setor da administração, esta pesquisa tem por objetivo apontar como o Job Rotation pode padronizar os níveis de divisão na Instituição. Adotou-se, portanto, como questão norteadora: como o Job Rotation pode

\footnotetext{
${ }^{1}$ Graduanda do curso de Administração.

${ }^{2}$ Graduando do curso de Administração.

${ }^{3}$ Graduanda do curso de Administração.

${ }^{4}$ Coorientador. Mestre em Engenharia de Processos. Pós-Graduando em Neuropsicopedagogia Institucional. Especialista em Gestão Estratégica de RH. Graduado em Administração e Pedagogia.

${ }^{5}$ Coorientador. Mestre em Ciência e Engenharia de Materiais. Especialista em Engenharia da Qualidade e Seis Sigma. Graduado em Tecnologia em Gestão da Qualidade.

${ }^{6}$ Orientador. Mestrado profissional em Engenharia de produção. Especialização em Gestão em Logística empresarial. Graduação em Administração com Ênfase em Marketing.
}

RC: 100583

Disponível em: https://www.nucleodoconhecimento.com.br/administracao/padronizaro-nivel 
padronizar o nível de serviço oferecido pelo setor administrativo? Utilizou-se para a pesquisa, a metodologia monográfica, também conhecida como estudo de caso, além das principais ferramentas a serem utilizadas, como: Job Rotation, com a finalidade de desenvolver competências e habilidades dos colaboradores; $5 \mathrm{~W} 2 \mathrm{H}$ no desenvolvimento de um plano de ação para implementar o que foi proposto no objetivo geral; e o brainstorming, como ferramenta de planejamento e solução de possíveis adversidades do artigo. Espera-se com a implantação da proposta interventiva, que os colaboradores do setor administrativo sejam capazes de ter uma visão holística dos processos na instituição, desenvolvendo novas habilidades e aperfeiçoando-se na comunicação, bem como padronizando-se, desta forma, a divisão oferecida pelo setor administrativo e suas funções.

Palavras chaves: Job rotation, Brainstorming, Padronização.

\section{INTRODUÇÃO}

Salienta-se que este trabalho tem como propósito principal expor os gargalos administrativos na instituição de ensino Colégio Dom Bosco - Leste, tendo como base de ferramenta de gestão da qualidade o Job rotation.

Pautou-se, após a descrição e análise da pesquisa de campo, ações que reverteriam as áreas críticas no setor administrativo, posto o baixo desempenho nesta área funcional, principalmente relacionado ao controle e à execução de determinadas tarefas. Desta forma, elaborou-se a seguinte questão norteadora: como o Job Rotation pode padronizar o nível de serviço oferecido pelo setor administrativo?

O intuito dessa ferramenta é minimizar gastos, colocar a empresa a altura do mercado referente ao seu ramo e implementar novas regras para tornar o trabalho de cada colaborador produtivo.

O Job rotation proporciona novas experiências e ganho de conhecimento sobre todas as áreas da instituição, focando também na descentralização de cargos

RC: 100583

Disponível em: https://www.nucleodoconhecimento.com.br/administracao/padronizaro-nivel 
hierárquicos, em que cada funcionário saberá tomar decisões baseadas no vasto valor da empresa adquirido em cada área.

Os objetivos específicos são: desenvolver um planejamento com treinamentos, detalhamento de atividades e cronogramas com trocas de funções; coordenar a rotação das funções administrativas, incentivando a meritocracia; avaliar os resultados do Job Rotation individual e coletivo para o desenvolvimento de KnowHow Coletivo; e proporcionar ganhos à empresa e ao colaborador, valorizando e motivando o mesmo ao desenvolvimento de carreira de acordo com seu desempenho.

Atrelado ao Job Rotation, adotou-se também o marketing para aumentar o número de novos clientes, tendo em vista a estrutura da organização, que mostra-se ser altamente capacitada para receber novos alunos, com disponibilidade de tecnologia e segurança de ponta, além de profissionais qualificados.

Este estudo propõe a implementação do modelo Job rotation na instituição, por meio da identificação da metodologia adequada para inserção da ferramenta, investigando também os motivos dos problemas e quais serão solucionados através das ações Job rotation.

Espera-se com esta proposta que a instituição obtenha melhor comprometimento nos setores, propiciando satisfação da coletividade interna e externa e corrigindo as inúmeras falhas apontadas na área administrativa da organização.

\section{FUNDAMENTAÇÃO TEÓRICA}

Entende-se por fundamentação teórica a pesquisa e citação de outras fontes científicas, como: artigos, livros, sites etc. para sustentar e embasar temas que são abordados ao longo do artigo. Portanto, a fundamentação teórica serve de fonte de informação e base teórica para explanação do tema principal.

RC: 100583

Disponível em: https://www.nucleodoconhecimento.com.br/administracao/padronizaro-nivel 
Para Zanella (2013), fundamentação teórica é uma síntese das pesquisas de outros autores que também pesquisaram sobre o mesmo assunto, suas críticas, teorias e levantamento de dados documentais.

Levantaram-se, neste artigo, dados para fundamentar o Job Rotation, e outros temas e ferramentas como o Brainstorming, que foram elencados como fundamentais para a pesquisa.

\subsection{PROCESSO DE INTRODUÇÃO DO JOB ROTATION}

Segundo Campion et al. (2013), o Job rotation são passagens niveladas de diferentes departamentos na organização.

Distingue-se o Job rotation como rotação no ambiente trabalhista, pois relaciona-se a modificações de diferentes áreas, normalmente relacionadas à categoria de cargos e outros benefícios, como: aumento salarial, ganho de experiências e de competências.

O termo Job Rotation traduzido significa rotação de trabalho, e ocorre quando a entidade realiza uma espécie de rodízio de tarefas e setores entre colaboradores de uma mesma empresa. Um modelo exemplar é um funcionário que atua no setor de marketing e com a rotação de cargos pode fazer parte da área administrativa e se desenvolver neste cargo. Através do Job Rotation o colaborador deixa sua função para exercer outra e favorecer aquela empresa se destacando na melhor área do seu desempenho.

Esta ferramenta potencializa habilidades e conhecimentos e prepara os profissionais para diferentes tomadas de decisão, fortalecendo-os em razão dos novos desafios e garantindo-Ihes diferentes rotinas. O Job Rotation permite o progresso constante do colaborador, e traz maior engajamento entre os funcionários relacionado com os objetivos da empresa.

RC: 100583

Disponível em: https://www.nucleodoconhecimento.com.br/administracao/padronizaro-nivel 
Desta forma, esta ferramenta beneficia tanto a entidade quanto o colaborador, pois o mesmo irá adquirir maior entendimento sobre a empresa; enriquecerá o networking dos colaboradores; os resultados serão mais expansivos; e a empresa terá seu quadro profissional completo pela vasta formação dos colaboradores.

Hakenes e Katolnik (2017) associam o Job Rotation com a motivação do colaborador para com a organização, como o incentivo à interação de outras atividades.

\subsection{PROCESSO DE INTRODUÇÃO DO 5W2H}

Santos et al. (2014) consideram que a ferramenta 5W2H proporciona informações para organizar a instituição, por meio da elaboração de um planejamento a ser seguido de fácil assimilação para seus colaboradores. Contudo, tendo em vista que uma má interpretação pode acarretar prejuízos imensuráveis, o mais eficaz é o acompanhamento rígido das programações a serem seguidas.

O 5W2H é a forma mais adequada para verificação de tarefas e atividades a serem cumpridas. Esta ferramenta funciona como uma lista de verificação e geralmente é usada para pôr projetos em prática ou realizar um controle na gestão da empresa.

Esta ferramenta tem como significado as iniciais em inglês que correspondem a cada etapa de perguntas, sendo: What? Quando deve ser feito? Who? Quem deve fazer? Where? Onde deve ser feito? Why? Por que deve ser feito? How? Como deve ser feito? How Much? Quanto isso irá custar?

Para Silva (2011), o propósito do 5W2H é excluir todo e qualquer risco à empresa, através da verificação do ambiente empresarial, identificando se existem condições adequadas para a prática desta ferramenta.

O 5W2H pode ser usado também na vida pessoal, como forma de estruturar todos os afazeres, ou planejar a vida para o futuro, a fim de obter metas e cumprir as 
realizações almejadas. Permite traçar variados caminhos por ser um método de fácil aplicação e pode ser executado em planilha ou tabela.

O mais importante é realizar de acordo com suas diretrizes para o alcance do resultado.

\subsection{PROCESSO DE INTRODUÇÃO DO BRAINSTORMING}

O brainstorming é uma ferramenta utilizada originalmente para solucionar problemas específicos, mas também pode ser usada para coletar ideias inovadoras, descobrir talentos, incentivar a participação e motivar colaboradores na criação de soluções para o dia a dia. A palavra brain (cérebro) e storming (tempestade) pode ser traduzida literalmente como tempestade de ideias, ou chuva de ideias. Consiste em reunir um grupo de pessoas com o propósito de promover diversas ideias para solucionar um problema, sendo estas, posteriormente, coletadas e analisadas para serem utilizadas pela gerência.

De acordo com Seleme e Stadler (2010), o Brainstorming é uma ferramenta em forma de reunião onde os participantes podem expor suas ideias de forma livre, ainda que pareça intangível.

Rennó (2013) afirma que o brainstorming é uma das principais ferramentas para solucionar problemas, onde as críticas são suspensas com a intenção de gerar uma cadeia de pensamentos e ideias.

\subsection{PROCESSO DE INTRODUÇÃO DE ESTRATÉGIAS ADMINISTRATIVAS}

Entende-se por estratégias administrativas ou empresariais, o conjunto de decisões com base em dados, tendo a finalidade de alcançar os objetivos da organização. Nesse contexto, estratégia é uma palavra que designa manobras utilizadas para alcançar objetivos, a qual por muito tempo foi utilizada nas organizações militares. Assim, pode-se entender por estratégia, um conjunto de atividades, e utilização de

RC: 100583

Disponível em: https://www.nucleodoconhecimento.com.br/administracao/padronizaro-nivel 
recursos de forma racional para atingir um objetivo específico (MENDES, 2015). No entanto, hoje ela é bastante difundida no contexto corporativo.

O planejamento estratégico geralmente é adotado entre as empresas para minimizar os riscos do negócio, e identificar suas potenciais vantagens competitivas e suas limitações frente ao mercado. Para isso, grande parte das empresas possuem uma missão, visão e princípios que norteiam as estratégias utilizadas por seus gestores.

Nesse contexto, existem 3 níveis de planejamento que podem ser adotados nas empresas: estratégico, tático e operacional. O planejamento no nível tático, que será abordado neste artigo, têm caráter mais detalhado, maior objetividade e realização de médio à longo prazo.

Barreto (2017) diz que as estratégias no nível tático utilizam-se de projetos, são executadas pelo nível operacional, em médio prazo, e possuem maior versatilidade em sua aplicação.

\subsection{PROCESSO DE INTRODUÇÃO DE CAPACIDADE E TREINAMENTOS}

Entende-se por capacitação o processo de desenvolver competências, por meio do conhecimento explícito ou tácito de aprendizado e treinamento. Constata-se que as organizações desenvolvem e aperfeiçoam suas competências conforme as necessidades mercadológicas e os objetivos da organização, e consequentemente, as competências individuais dos colaboradores.

Portanto, é necessário para uma empresa desenvolver competências organizacionais, e para isso ela precisa desenvolver as competências individuais dos seus colaboradores através de treinamentos, e/ou por meio da contratação de indivíduos que já possuam tais competências.

Para Derner (2013), as estratégias mercadológicas estão relacionadas às competências tanto organizacional como individual, independente da hierarquia.

RC: 100583

Disponível em: https://www.nucleodoconhecimento.com.br/administracao/padronizaro-nivel 
Constatou-se que o treinamento e a capacitação são processos para desenvolver habilidades e competências.

No entanto, para o uso eficiente do treinamento é necessário saber os motivos e o que se busca com este investimento.

Conforme Paes (2011), o primeiro passo para implantar um treinamento é identificar as necessidades da organização, em que ela precisa melhorar para atingir seus objetivos.

Portanto, faz-se necessário identificar os pontos fracos da empresa e dos colaboradores, e analisar, frente aos objetivos estratégicos, qual tipo de treinamento melhor se adequa a situação.

\subsection{PROCESSO DE INTRODUÇÃO DE ENRIQUECIMENTO DE} TAREFAS

Compreende-se por enriquecimento de tarefas ou cargos, o aumento da complexidade ou tarefas e atividades executadas por um determinado colaborador. Este enriquecimento aumenta o conhecimento e as habilidades do colaborador, proporcionando maior autonomia e visibilidade. Nota-se que há uma relação direta na motivação do trabalho ao aumentar o grau de complexidade de um cargo ou função.

Em conformidade com Hetzberg (apud Chiavenato, 2014), o sentimento de crescimento, reconhecimento profissional e auto realização dependem das tarefas que um indivíduo realiza, e está relacionada diretamente aos fatores motivacionais.

Para Pezzi e Figueiredo (2013), os cargos são definidos pela estrutura organizacional, suas atribuições e sua relação com outros cargos.

RC: 100583

Disponível em: https://www.nucleodoconhecimento.com.br/administracao/padronizaro-nivel 
Considera-se um cargo o complexo de atividades exercidas por determinado colaborador e, consequentemente, atividades como conjunto de tarefas e as tarefas como elementos que utilizem o esforço humano.

\section{MATERIAIS E MÉTODOS}

Define-se materiais como os instrumentos de pesquisa e os métodos como um processo de verificação da verdade em algum campo da ciência, utilizados para se alcançar um objetivo específico.

Conforme Libório e Terra (2015), o método pode ser entendido como premissas básicas e fundamentais para uma investigação imparcial e verídica.

Utilizou-se como instrumentos de pesquisa, principalmente obras de outros autores, como livros e artigos relacionados ao tema da pergunta problema. Já o método utilizado foi o monográfico, também conhecido como estudo de caso, onde por meio de um estudo de caso isolado podemos considerá-lo uma representação de outros.

\subsection{PROCEDIMENTOS METODOLÓGICOS}

Considera-se fundamental o procedimento metodológico dentro de um artigo para a otimização de materiais e métodos a serem utilizados, a fim de obter a veracidade de dados e resultados da pesquisa.

De acordo com Aragão e Neta (2017), o método é um composto de estágios coordenados para averiguar a verdade dentro de uma determinada ciência, e o procedimento metodológico é a aplicação adequada de atividades para utilização do método.

Para este artigo foi utilizado a pesquisa bibliográfica, a fim de extrair uma revisão crítica embasada em obras de diversos autores com relação ao tema desta pesquisa. 


\subsubsection{QUANTO À NATUREZA}

A abordagem e meta principal desta metodologia é compreender a alegação de tal fenômeno. Desta forma, a modalidade utilizada para essa pesquisa foi a descritiva para analisar os fatos e averiguar todas as informações instigantes.

Segundo Zanella (2013), para compor as razões da pesquisa, no que se fundamenta as investigações de análise qualitativa, identifica-se em base, o não aproveitamento da ferramenta estatística na pesquisa de dados. Esta análise teórica-empírica objetiva conceder base científica.

Para Kauark et al. (2010), esse tipo de análise oferece uma ligação entre o mundo externo e o principal elemento investigado, promovendo afinidade entre o propósito e a parcialidade do sujeito improvável em ser representado em números.

No modelo qualitativo, são coletados dados de autodomínio, menos escrupuloso e menos intuitivo. O pesquisador realiza a pesquisa de campo e faz sua conclusão das respostas obtidas dos entrevistados.

\subsubsection{QUANTO AOS FINS}

Esta pesquisa pode ser classificada como aplicada, pois poderá ser utilizada e implementada na problemática da intervenção deste artigo. Tendo em vista um déficit no setor administrativo, propôs-se a utilização do Job rotation e a padronização do nível de divisão da ISMA (Inspetoria Salesiana Missionária da Amazônia).

Para Marconi e Lakato (2017), a pesquisa descritiva tem a finalidade de sintetizar dados e analisar características de acontecimentos e fatos acerca do objeto da pesquisa.

Em concordância, Gil (2002) menciona que a pesquisa descritiva é utilizada para o processamento de dados e informações obtidas. A pesquisa descritiva tem como

RC: 100583

Disponível em: https://www.nucleodoconhecimento.com.br/administracao/padronizaro-nivel 
objetivo evidenciar características e possíveis variáveis de um determinado fenômeno e sua relação com as possíveis variáveis.

\subsubsection{QUANTO AOS MEIOS}

Em concordância com Zanella (2013), a principal vantagem é permitir ao pesquisador uma cobertura mais ampla do que se pretende pesquisar.

De acordo com Vergara (2016), a pesquisa bibliográfica é uma investigação sistematizada e embasada em materiais difundidos na comunidade científica para análise.

Destaca-se como o principal meio de coleta de dados, livros e artigos para a fundamentação teórica e a produção de um pensamento crítico embasado. Desta forma, a pesquisa se classifica como bibliográfica.

\subsection{CARACTERIZAÇÃO DA EMPRESA}

Elaborou-se uma pesquisa de campo na instituição estudada, onde houve uma projeção atual da Inspetoria Salesiana Missionária da Amazônia que detém o nome fantasia de Colégio Dom Bosco, na unidade leste que localiza-se na Av. Cosme Ferreira, $\mathrm{n}^{\circ}$ 5122, no bairro Zumbi dos Palmares, na cidade de Manaus/Am- CEP: 69.83.-000.

A organização atua no segmento de serviços na área educacional. O Colégio Dom Bosco- Leste iniciou suas atividades em 1983, mas só em 1994 foram abertas vagas para ensino médio. Atualmente, a organização conta com 31 profissionais que englobam seu corpo docente.

A equipe pedagógica é composta de 02 (duas) pedagogas, sendo uma do $1^{\circ}$ ao $7^{\circ}$ ano do ensino fundamental e outra do $8^{\circ}$ ano do ensino fundamental ao ensino médio, 01 (uma) assistente de pátio, 01 (uma) bibliotecária, 01 (um) auxiliar de biblioteca, 01 (uma) equipe pastoral e 01 (uma) diretora pedagógica. 
A administração da organização conta com 01 (um) diretor geral, 01 (um) administrador financeiro, 01 (uma) assistente de cobrança, 01 (um) administrador do setor pessoal, 01 (um) caixa, 01 (uma) assistente de marketing, 01 (uma) secretária, 01 (uma) auxiliar de secretaria, 01 (uma) recepcionista, 01 (um) técnico em informática, 01 (um) auxiliar de reprografia, 07 (sete) colaboradores na limpeza, 01 (um) técnico em manutenção e 04 (quatro) vigias.

O serviço prestado na área educacional da ISMA tem como base o catolicismo com proposta pedagógica embasada na rede salesiana de escolas, onde buscam promover educação de qualidade, garantindo valores ao desenvolvimento intelectual, familiar e da fé na religião católica e construindo um ser humano comunitário. Enfatizando significativamente a figura de Dom Bosco que busca passar a razão, religião, amorevolezza ou amor educativo.

No que diz respeito à estrutura física da organização, esta possui área total de $122.028,65 \mathrm{~m}^{2}$, que dispõe de um complexo educacional com ensino fundamental, médio, faculdade, técnico e projetos sociais.

O Colégio Dom Bosco compartilha da concepção de que a educação é uma forma de prevenção da marginalização e de melhoria da sociedade, como outras obras de promoção social de assistência.

\section{RESULTADOS E DISCUSSÕES}

Com base nos dados coletados na Inspetoria Salesiana Missionária da Amazônia (Dom Bosco Leste), durante o diagnóstico organizacional, foi possível mapear por área funcional aquelas com maior déficit de desempenho e as que destacam-se positivamente.

Observa-se no gráfico 1 que as áreas funcionais com melhor desempenho foram operações e finanças, e as com pior desempenho foram o marketing e a administração. 
Justifica-se a escolha do setor administrativo como o foco da pesquisa por ter o pior desempenho médio dentre as áreas funcionais da empresa, com 1,9 pontos.

Gráfico 1- Média de desempenho por área

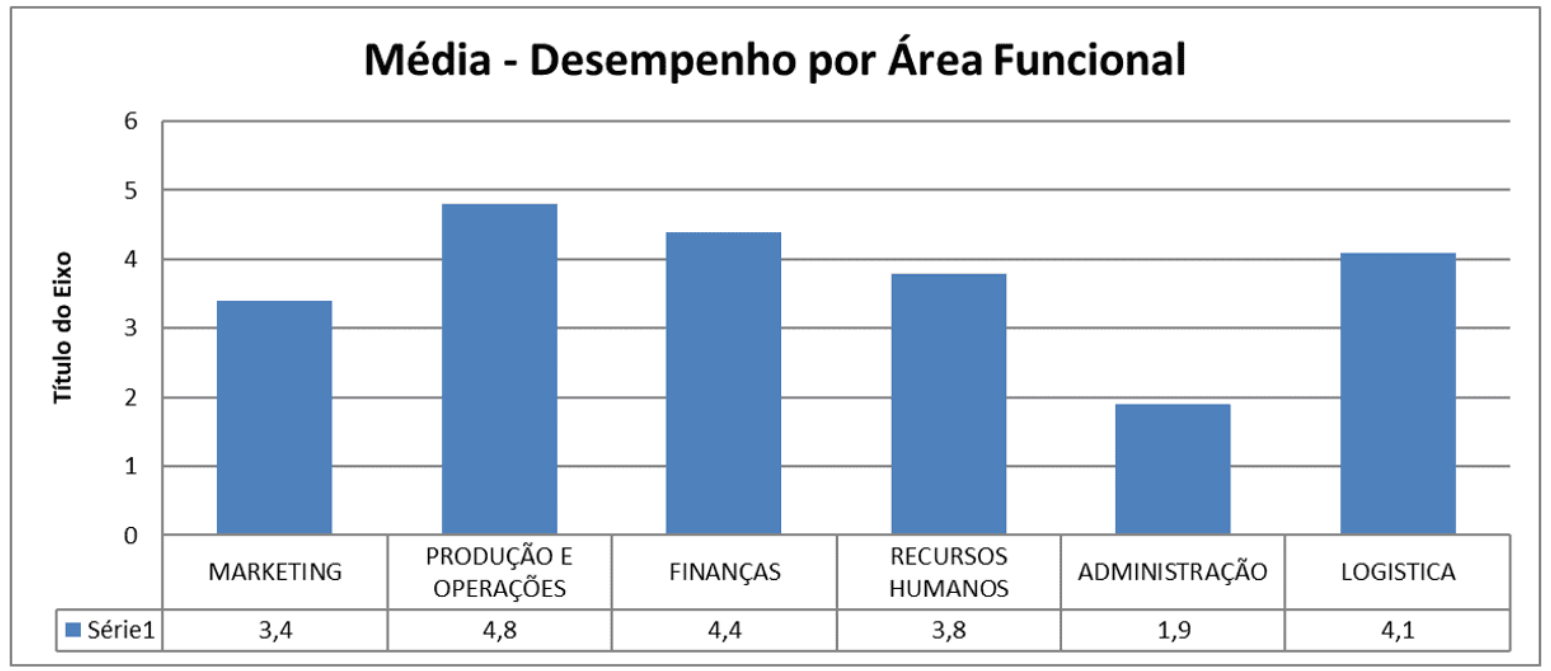

Fonte: Elaborado pelos autores com base no diagnóstico organizacional, 2020.

Identificam-se no quadro abaixo, os critérios de desempenho que foram utilizados para atribuir a nota média da área mostrada no gráfico 1 .

Percebe-se que suas maiores dificuldades estão no que tange a coleta, processamento e análise de dados que consideramos relevantes para a função. Seguindo-se de um desempenho mediano na criação de métricas de mensuração do desempenho dos colaboradores.

Quadro 1: Área funcional - Administração

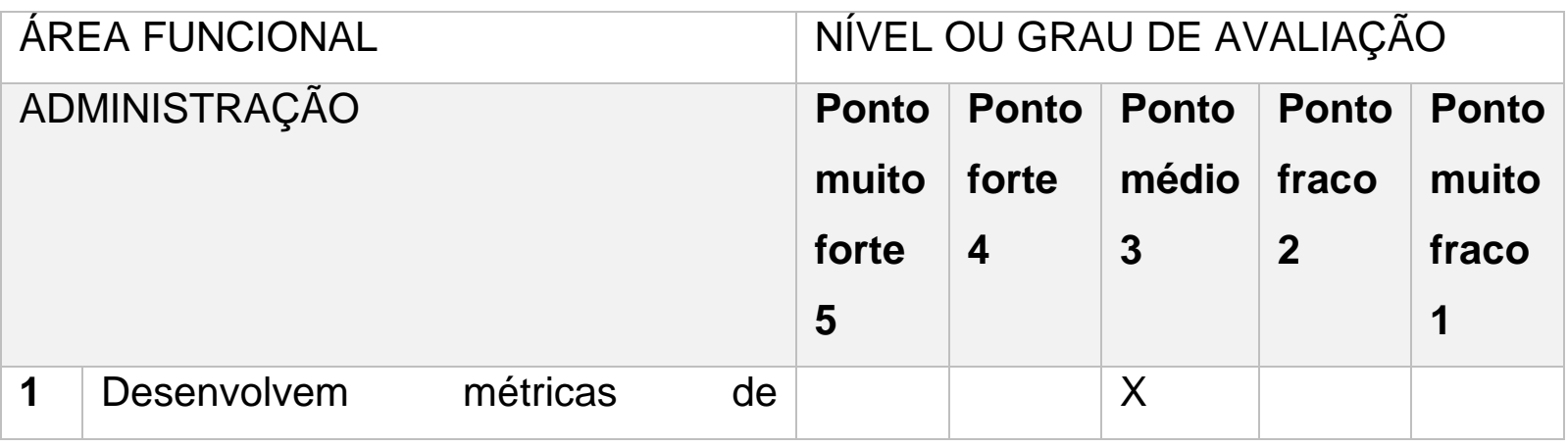

RC: 100583

Disponível em: https://www.nucleodoconhecimento.com.br/administracao/padronizar$\underline{\text { o-nivel }}$ 


\begin{tabular}{|c|c|c|c|c|c|c|}
\hline & desempenho dos colaboradores: & & & & & \\
\hline 2 & $\begin{array}{l}\text { Avaliam o desempenho de serviços } \\
\text { de limpeza e manutenção: }\end{array}$ & $X$ & & & & \\
\hline 3 & $\begin{array}{l}\text { Organizam informações de } \\
\text { processos de dados e incluem no } \\
\text { planejamento: }\end{array}$ & & & & $X$ & \\
\hline 4 & $\begin{array}{l}\text { Avaliam ferramentas de controle de } \\
\text { cada atividade realizada: }\end{array}$ & & $X$ & & & \\
\hline 5 & $\begin{array}{l}\text { Expõem suas políticas } \\
\text { organizacionais: }\end{array}$ & & & & $X$ & \\
\hline 6 & Realizam cadeia de comando clara: & $X$ & & & & \\
\hline 7 & $\begin{array}{l}\text { Aceitam desafios e sabem gerenciar } \\
\text { conflitos: }\end{array}$ & & $X$ & & & \\
\hline 8 & $\begin{array}{l}\text { Utilizam ferramentas para avaliar } \\
\text { pontos fortes e fracos: }\end{array}$ & & & & $X$ & \\
\hline 9 & $\begin{array}{l}\text { Realizam pesquisa de oportunidades } \\
\text { e ameaças: }\end{array}$ & & & & $X$ & \\
\hline 10 & $\begin{array}{l}\text { O gestor auxilia na execução do } \\
\text { planejamento estratégico: }\end{array}$ & $X$ & & & & \\
\hline TO & $\mathrm{TAL}(\Sigma)$ & 0 & 8 & 3 & 8 & 0 \\
\hline MÉ & DIA POR GRAU (POR COLUNA) & 0 & 0,8 & 0,3 & 0,8 & 0 \\
\hline \multicolumn{2}{|c|}{ DESEMPENHO DA ÁREA ( } & \multicolumn{5}{|c|}{1,9} \\
\hline
\end{tabular}

Fonte: Elaborado pelos autores com base no diagnóstico organizacional, 2020.

Conclui-se após as constatações dos parágrafos anteriores, a necessidade de melhorias no setor administrativo da empresa. Portanto, desenvolveu-se um plano de ação para a implementação do Job Rotation na padronização do nível de divisão no setor. 


\subsection{PLANEJAMENTO DE AÇÕES}

Considerando a área com menor desempenho e a problemática a ser trabalhada, desenvolveu-se um plano de ação para executar o que foi proposto. A finalidade deste planejamento é criar ações práticas que possam ser trabalhadas ou utilizadas na empresa, abrangendo o tema do problema desenvolvido durante a pesquisa.

Sabe-se que existem diversas ferramentas para o desenvolvimento de ações interventivas. Nesta pesquisa utilizou-se o $5 \mathrm{~W} 2 \mathrm{H}$, que consiste em planejar ações respondendo às perguntas essenciais para elaboração de qualquer atividade. Segue abaixo o quadro de ações interventivas que foi adotado para a implantação do Job Rotation no Dom Bosco Leste.

Quadro 2: ações interventivas

\begin{tabular}{|l|l|l|l|l|}
\hline $\mathbf{1}$ & $\begin{array}{l}\text { Ações Interventivas } \\
\text { Criar uma descrição das atividades } \\
\text { estratégicas administrativas }\end{array}$ & Fevereiro/2022 & 20 dias & $\begin{array}{l}\text { Custo } \$ \\
1.000,00\end{array}$ \\
\hline $\mathbf{2}$ & $\begin{array}{l}\text { Promover eventos de capacitação } \\
\text { atraentes para altos dirigentes }\end{array}$ & Março/2022 & 15 dias & $\mathrm{R} \$$ \\
\hline $\mathbf{3}$ & $\begin{array}{l}\text { Estruturar um plano de treinamento } \\
\text { voltado }\end{array}$ & Abril/2022 & 15 dias & $\mathrm{R} \$$ \\
\hline $\mathbf{4}$ & $\begin{array}{l}\text { Estabelecer um cronograma para fazer a } \\
\text { rotação de cargos }\end{array}$ & Abril/2022 & 700,00 \\
\hline $\mathbf{5}$ & $\begin{array}{l}\text { Usar brainstorming para levantar } \\
\text { possíveis situações, usar para } \\
\text { integrantes durante reuniões para que } \\
\text { esses possam expor suas opiniões e } \\
\text { ideias }\end{array}$ & & $\mathrm{R} \$$ \\
\hline
\end{tabular}


6 O incentivo ao reconhecimento do \begin{tabular}{l|l|l} 
Junho/2022 & 30 dias & $\mathrm{R} \$$
\end{tabular} desempenho e do mérito individual na mobilidade vertical do setor administrativo

Fonte: Elaborado pelos autores, 2021.

Portanto, as ações interventivas mostradas no quadro acima foram desenvolvidas para implantar o Job Rotation no setor administrativo, de forma clara e com riqueza de detalhes, a fim de torná-las viáveis e simples de serem executadas.

\subsection{CRIAR UMA DESCRIÇÃO DAS ATIVIDADES ESTRATÉGICAS ADMINISTRATIVAS}

Esta ferramenta é um método usado para alcançar um determinado objetivo, relacionado ao planejamento, adequação de acordo com o mercado, alcance de novos clientes, fidelização de clientes já existentes e organização do ambiente trabalhista.

Contudo, é algo fundamental que este seja utilizado por toda equipe da entidade, uma vez que desenvolve habilidades de gerenciamento e possibilita o alcance da meta, missão e visão que a organização possui.

Quadro 3: Criar uma descrição das atividades estratégicas administrativas

Criar uma descrição das atividades estratégicas administrativas

O que? Descrição das atividades estratégicas administrativas.

Por quê? Para especificar cada atividade que está sendo realizada.

Onde? No Colégio Dom Bosco-Leste.

Quando? Segunda semana de fevereiro de 2022.

Quem? Departamento administrativo.

RC: 100583

Disponível em: https://www.nucleodoconhecimento.com.br/administracao/padronizaro-nivel 
Como? Por internação de consultor empresarial que irá no primeiro momento observar cada detalhe das atividades administrativas e verificar gargalos que a empresa enfrenta.

Quanto? R\$1.000,00

Fonte: Elaborado pelos autores em agosto/2021.

Observa-se que os colaboradores devem verificar cada atividade realizada com detalhamento e se há uma programação para execução da mesma, onde determinada pessoa responsável pelo setor deverá desempenhar a função de forma correta, se atentando aos indesejáveis gargalos.

\subsection{PROMOVER EVENTOS DE CAPACITAÇÃO ATRAENTES PARA ALTOS DIRIGENTES}

Considera-se vital para a implementação de qualquer projeto ou processo a compreensão, aprovação e incentivo pela alta gerência de qualquer empresa.

Levantaram-se algumas tarefas para a execução desta ação. Fez-se necessário, antes de tudo, escolher uma instituição de capacitação confiável e fazer um orçamento com limite de gastos previamente estabelecido com intuito de trazer para a instituição um profissional gabaritado que ministre palestras ou workshops para a gerência.

A promoção de eventos que sejam atraentes e ao mesmo tempo que capacitem este público, os profissionalizam e apoiam projetos como o Job rotation

Quadro 4: promover eventos de capacitação atraentes para altos dirigentes

Promover eventos de capacitação atraentes para altos dirigentes

O que? Eventos atraentes para altos dirigentes.

Por quê? Para capacitá-los.

Onde? Auditório do Colégio Dom Bosco-Leste

RC: 100583

Disponível em: https://www.nucleodoconhecimento.com.br/administracao/padronizar$\underline{\text { o-nivel }}$ 
Quando? 01/03/2022.

Quem? Empresa de capacitação.

Como? Ministração de palestras e workshops no meio tempo de 2 semanas.

Quanto? $R \$ 3377,20$.

Fonte: Elaborados pelos autores de 2021.

Corrobora-se para a implementação de qualquer projeto ou processo, a compreensão, aprovação e incentivo pela alta gerência de qualquer empresa. Portanto, a promoção de eventos que sejam atraentes e ao mesmo tempo capacitantes para este público é crucial no início desse investimento.

\subsection{ESTRUTURAR UM PLANO DE TREINAMENTO VOLTADO A TÉCNICAS DE VENDAS}

Acredita-se que a habilidade de vendas é fundamental para todo e qualquer negócio que tenha como objetivo a geração de lucro. Sabendo-se disto, pontuou-se como uma das habilidades a serem trabalhadas com parte da equipe administrativa, principalmente com recepcionistas e atendentes.

Tendo em vista a necessidade de capacitar funcionários, alguns passos devem ser seguidos. Inicialmente, estabelecer um orçamento de quanto pode ser gasto $(\mathrm{R} \$ 800,00)$, pesquisar e escolher uma instituição confiável para este tipo de treinamento na modalidade à distância, organizar a sala de informática e selecionar os dias em que serão feitos os treinamentos.

Quadro 5: Estruturar um plano de treinamento voltado a técnicas de vendas.

Estruturar um plano de treinamento voltado a técnicas de vendas.

O que? Planejar treinamento orientado para vendas.

Por quê? Capacitação de colaboradores.

Onde? Sala de informática do Colégio Dom Bosco-Leste 
Quando? $01 / 04 / 2022$.

Quem? Empresa de capacitação.

Como? Através de cursos com plataformas para Ensino a Distância.

Quanto? R $\$ 800,00$

Fonte: Elaborado pelos autores em agosto/2021.

Destaca-se a importância deste treinamento para a melhoria não somente em processos, mas também no desenvolvimento pessoal dos colaboradores. Espera-se com este treinamento, maior engajamento para a captação de clientes e recursos para a instituição.

\subsection{ESTABELECER UM CRONOGRAMA PARA FAZER A ROTAÇÃO DE CARGOS}

Compreende-se como cronograma, enquanto um gerenciador de tarefas e projetos, um checklist com marco de dependências a ser seguido, pelo qual controla-se a realização de eventos programados.

Podendo referir-se à representação gráfica ou não, é uma ferramenta de gestão pessoal que pode ser usada para gerenciar algo que tenha tempo determinado.

Quadro 6: estabelecer um cronograma para fazer a rotação de cargos

Estabelecer um cronograma para fazer a rotação de cargos

O que? Cronograma para rotação de cargos .

Por quê? Para implementar o rodízio de tarefas.

Onde? No Colégio Dom Bosco- Leste .

Quando? Primeira semana de abril de 2022.

Quem? Todos os colaboradores do Colégio Dom Bosco- Leste.

Como? Através de uma ferramenta chamada de Job Rotation, onde cada colaborador irá conhecer todos os departamentos, realizando um rodízio

Disponível em: https://www.nucleodoconhecimento.com.br/administracao/padronizaro-nivel 
e aquilinos conhecimento de cada área.

Quanto? R\$900,00

Fonte: Elaborado pelos autores em agosto/2021.

Analisou-se a necessidade da implementação deste método para que ocorra uma boa comunicação em diferentes departamentos, observando as perspectivas dos colaboradores quanto ao desempenho em outras áreas e a chance de crescimento dos mesmos.

\subsection{USAR BRAINSTORMING PARA LEVANTAR POSSÍVEIS SITUAÇÕES, USAR PARA INTEGRANTES DURANTE REUNIÕES PARA QUE ESSES POSSAM EXPOR SUAS OPINIÕES E IDEIAS}

O Brainstorming é uma ferramenta voltada para a solução de problemas e inovação, com baixo custo, eficiente e que pode ser utilizada por qualquer gestor, desde que saiba organizar, analisar e selecionar as melhores ideias propostas.

A dinâmica desta ferramenta, como o nome sugere, é criar uma chuva de ideias de pessoas que trabalham e convivem com os problemas que se busca a solução. Podendo, essas ideias, serem coletadas através de reuniões, caixinhas de sugestões e outros métodos. O gestor organiza as ideias, analisa a viabilidade, prós e contras de cada, e filtra as melhores para utilizá-las naquilo em que se propôs inicialmente.

Quadro 7: Brainstorming

Usar brainstorming para levantar possíveis situações, usar para integrantes durante reuniões para que esses possam expor suas opiniões e ideias.

O que? Ferramenta para obter ideias.

Por quê? Para utilizar as melhores ideias como ferramentas na elaboração do Job Rotation.

RC: 100583

Disponível em: https://www.nucleodoconhecimento.com.br/administracao/padronizaro-nivel 
Onde? Sala de Reunião do Colégio Dom Bosco-Leste.

Quando? 01/05/2022.

Quem? Gestores, e colaboradores do setor administrativo.

Como? Através de reuniões incentivando a criatividade para ideias e soluções de problemas.

Quanto? 2 á 6 horas de reunião.

Fonte: Elaborado pelos autores em agosto/2021.

Optou-se por uma reunião, com o objetivo de identificar e tentar solucionar previamente as dificuldades na execução da rotação de cargos. A reunião ocorrerá na sala de reuniões, contando com a participação dos envolvidos no setor administrativo, e serão abordadas possíveis dúvidas e dificuldades, incentivando cada um a desenvolver soluções.

Gera-se, desta forma, soluções para eventuais desafios na execução do Job rotation na empresa, que é a finalidade desta ação.

\subsection{O INCENTIVO AO RECONHECIMENTO DO DESEMPENHO E DO MÉRITO INDIVIDUAL NA MOBILIDADE VERTICAL DO SETOR ADMINISTRATIVO}

Estabeleceu-se um sistema de reconhecimento meritocrático e individual para auxiliar na coordenação e execução de todo o planejamento do Job Rotation, incentivando a participação e dedicação dos colaboradores para que o programa seja efetivamente aderido dentro da empresa.

Quadro 8: Incentivo ao reconhecimento do desempenho e do mérito individual.

O incentivo ao reconhecimento do desempenho e do mérito individual na mobilidade vertical do setor administrativo.

O que? Incentivos financeiros para metas alcançadas dentro do programa de 


\begin{tabular}{|c|c|}
\hline & Job Rotation. \\
\hline Por quê? & $\begin{array}{l}\text { Incentivar colaboradores a se envolverem, aprenderem e se } \\
\text { desenvolverem em novas funções na empresa. }\end{array}$ \\
\hline Onde? & Setor administrativo. \\
\hline Quando? & 01/06/2022. \\
\hline Quem? & Colaboradores do setor administrativo. \\
\hline Como? & $\begin{array}{l}\text { Através de pagamentos em espécie ou através de rodízios pagos com } \\
\text { acompanhantes aos colaboradores que se empenharem em funções } \\
\text { novas estabelecidas pelo programa. }\end{array}$ \\
\hline Quanto? & $\mathrm{R} \$ 500,00$ (limite). \\
\hline
\end{tabular}

Fonte: Elaborado pelos autores em agosto/2021.

Adotou-se para o sistema de reconhecimento metas e obrigações como: engajamento, pró-atividade e eficácia nas atividades, sendo remunerados financeiramente os colaboradores que cumprirem essas metas propostas. Estabeleceu-se o valor para esta ação de no máximo $\mathrm{R} \$ 500,00$.

Espera-se deste incentivo, maior engajamento no Job Rotation, eficiência e redução de objeções, frente às mudanças estabelecidas.

\section{CONSIDERAÇÕES FINAIS}

O estudo de campo foi realizado na instituição de ensino Colégio Dom Bosco Leste, onde atuam na área educacional, oferecendo qualidade na educação, infraestrutura e crescimento pessoal.

Com base na coleta de dados apresentada pelos profissionais da organização, foi encontrado um déficit de desempenho na área administrativa do negócio, assim, o objetivo geral deste caso foi a implementação de novos métodos para qualificar a empresa segundo o mercado, bem como buscar novos clientes. 
Como pergunta problema, o estudo buscou elucidar: como o Job Rotation pode padronizar o nível de serviço oferecido pelo setor administrativo? Desenvolveu-se, portanto, uma proposta de ação interventiva para introduzir as práticas necessárias à capacitação de todos os colaboradores, para executar as atividades do setor de forma padronizada, atingindo assim os resultados esperados no estudo.

Desta forma, os objetivos específicos se basearam em desenvolver um planejamento com treinamentos, detalhamento de atividades e cronogramas com trocas de funções; coordenar a rotação das funções administrativas, incentivando a meritocracia; e avaliar os resultados do Job Rotation individual e coletivo para o desenvolvimento de Know-How Coletivo.

Esta nova estruturação tornou-se imprescindível para solução da problemática inaugural, que almejava a ordenação no desenvolvimento de pessoas e departamentos, bem como, a eficácia da área administrativa em padronização e habilidades por meio da ferramenta Job Rotation.

Em síntese, com os métodos apontados, criou-se uma descrição das atividades estratégicas administrativas; promoveu-se eventos de capacitação atraentes para altos dirigentes, como palestras e workshops; estruturou-se um plano de treinamento voltado a técnicas de vendas através de cursos com plataformas para ensino a distância, onde cada colaborador conheceu todos os departamentos, realizado por rodízio e conhecimento adquirido de cada área; estabeleceu-se um cronograma para fazer a rotação de cargos; utilizou-se brainstorming para levantar possíveis situações, incentivos ao reconhecimento do desempenho e do mérito individual para metas alcançadas aos colaboradores que empenharam-se em funções novas estabelecidas pelo programa; e oportunizou satisfação ao público em geral, aumentando assim os lucros da organização.

\section{REFERÊNCIAS}

ARAGÃO, J. W.; NETA, M. A. H. M. Metodologia Científica. Salvador. UFBA, 2017. 
BARRETO, J. M. Introdução à Administração. Salvador: UFBA. 2017.

CAMPION, M. A. et al. Career-Related Antecedents and the Outcomes of Job Rotation. Academy Management Journal, 2013.

CHIAVENATO, I. Teoria geral da administração. 9. ed. Barueri: Editora Manole, 2014.

DERNER, D. Gestão estratégica de pessoas. Salvador: UNIFACS. 2013.

GIL, A. C. Como elaborar projetos de pesquisa. 2. ed. São Paulo. Editora Atlas S.A, 2002.

HAKENES, H.; KATOLNIK, S. On the incentive effects of job rotation. European Economic Review, 2017.

KAUARK, F. et al. Metodologia da pesquisa: guia prático. Itabuna. Via Litterarum, 2010.

LIBÓRIO, D.; TERRA, L. Metodologia científica. São Paulo. Rede Internacional de Universidades Laureate, 2015.

MARCONI, M. A.; LAKATOS, E. M. Fundamentos da metodologia Científica. 8. ed. São Paulo. Editora Atlas S.A, 2017.

MENDES, G. H. de S. Administração estratégica. Florianópolis: UFSC. 2015.

PAES, K. D. Gestão de pessoas. Natal: Edunp. 2011.

PEZZI, C. R.; FIGUEIREDO, P. A. Práticas de Recursos Humanos. Curitiba: Instituto Federal do Paraná, 2013.

SELEME, R.; STANDLER, H. Controle da qualidade: as ferramentas essenciais. 2. ed. Curitiba: IBPEX. 2012. 
VERGARA, S. C. Projetos e relatórios de pesquisa em administração. 16. ed. São Paulo. Editora Atlas S.A, 2016.

ZANELLA, L. C. H. Metodologia da pesquisa. 2 Ed. Florianópolis: UFSC, 2013.

Enviado: Outubro, 2021.

Aprovado: Novembro, 2021. 